CASE 2.-The patient, a woman aged 29 , with no previous history of indigestion or any other trouble, was brought into hospital 12 hours after the rupture of the duodenal ulcer had occurred. The symptoms were typical and her condition was bad. Pulse very weak and rapid.

On opening the abdomen a small anterior perforation in the first part of the duodenum was at once found and closed by suture; the pelvis was drained as in Case $1 . \quad$ Eight days subsequently a secondary rupture occurred, but the patient was now in a much better condition, and being in hospital was re-operated upon within half an hour. The duodenum was occluded by plication, a posterior gastro-enterostomy was done, and the patient promptly recovered and has remained well.

Case 3.-The patient, a woman aged 45 , on whom I had performed panhysterectomy five years previously for a $12 \mathrm{lb}$. fibroid of the uterus, was admitted with a recently perforated duodenal ulcer. Her condition was good. The perforation was closed by suture, the duodenum occluded by plication, and a posterior gastro-enterostomy was done. A rapid recovery was made and she has remained well.

Cases $I$ and 2 would probably have died had immediate gastro-enterostomy been done. Case 1 would probably have recovered just as well had a gauze plug been substituted for the omental one; but Mr. Corner recommends that his gauze plug be removed under an anæsthetic in 48 hours, whereas when an omental plug is made use of the cigarette drain can be removed in five days without an anæsthetic.

San Bernardino, California.

\section{A CASE OF EXTRAORDINARY TRAUMATIC DEFORMITY WITH OEDEMA.}

By P. C. Perham Taylor, L.R.C.P. \& S. Edin., \&C.

THE patient, a woman aged 46 years, was born at Whatting, Sussex. At the time of birth she was quite natural. When about 2 years old, on her mother taking her out of bed one night, she fell. There was no history of any previous fall or accident. All use went out of her legs. She was put to bed, and the doctor was sent for. She lay unconscious for about six weeks. On recovery $h \in r$ legs and arms were deformed, but there was no swelling.

About three year a $\mathrm{g}$ o swelling of the legs set in, and they have been g radually getting into their present condition as shown in the photograph. She came into the Hailsham Union Infirm. ary at that time. She is able to sit up in bed, and amuses herself with fancy work, \&c.

Her present condition is as follows. She is most cheerful and suffers no pain, only a feeling of heaviness in the legs, which is relieved when she is tapped, about every six weeks. The heart and lungs are normal. The bowels act only with aperients. The urine is normal; no albumin. She has always been regular, the flow being abundant and painful, until the menopause, which occurred about two years ago. There is no swelling of the arms or hands, though the latter are deformed, as is shown in the photograph reproduced.

Family history: Her father died at the age of 51 years from Bright's disease. Her mother is alive, aged 74, and suffers from her heart. Of her brothers, two are alive, aged respectively 41 and 38, both being healthy; two are dead, one at 21 from phthisis and one in infancy. One sister is alive, aged 56, and is healthy; three died in infancy. There is no history of any paralysis in the family.

I am indebted to Mr. F. S. Parker, chemist, Highstreet, Hailsham, for the photograph.

Hailsham, Sussex.

\section{AN UNUSUAL CASE OF PERFORATED ULCER OF THE OESOPHAGUS.}

By Graham W. Christie, M.B., Ch.B. Edin., RESIDENT MEDICAL OFFICER, THE INFIRMARY, STOCKPORT.

THE patient, aged 60, was admitted to Stockport Infirmary on June 21st, at 1.30 A.M., suffering from intense dyspncea and complaining of acute pain all over the abdomen. The history was that he was in perfect health until 8.30 P.M. on the previous evening, when after a few glasses of beer he was taken ill suddenly with violent pain in the epigastrium, which doubled him up and was soon followed by an attack of vomiting.

On admission the patient was suffering from collapse and intense dyspnœa, simulating a bad attack of asthma. The temperature was $99^{\circ} \mathrm{F}$., the pulse-rate 125 , and the respirations shallow and 50 per minute. What he complained of most was intense pain in the epigastric region and acute stabbing pain in the back. His condition differed, however, from that experienced in perforated gastric ulcer in that he was most comfort. able and had least pain when he sat bolt up. right in bed.

On examin. ing the abdo. men there was found to be practically no movement on respiration, and it was rigid all over. There was marked tenderness on palpation over the epigas. trium, and the most tender

A, Left hand; B, Left femur; C, Left tibia; $\mathbf{E}$, Left big toe; D, Left foot: F, Right femur; G, Right tibia ; H, Right heel; $\mathrm{K}$, Right foot. It is impossible to tell, owing to the swelling, where the left knee is, as the patella cannot be felt. part of all was in the upper 